\title{
Assimilation experiments with CHAMP GPS radio occultation measurements
}

\author{
By S. B. HEALY* and J.-N. THÉPAUT \\ European Centre for Medium-Range Weather Forecasts, Reading, UK
}

(Received 14 December 2004; revised 17 June 2005)

\section{SUMMARY}

A one-dimensional bending-angle observation operator for assimilating GPS radio occultation (RO) measurements has been integrated into the ECMWF four-dimensional variational assimilation (4D-Var) system. We have performed forecast impact experiments with 60 days of CHAMP RO measurements, in addition to the latest set of conventional and satellite data that are assimilated operationally, including radiances from the Atmospheric Infrared Sounder. It is demonstrated that the CHAMP measurements provide extremely good temperature information in the upper troposphere and lower stratosphere. In the southern hemisphere ( $\mathrm{SH})$, they produce a clear, statistically significant improvement in the r.m.s. forecast fit to radiosonde measurements over the day 1 to day 5 forecast range at 300, 200, 100 and $50 \mathrm{hPa}$. An improved r.m.s. fit to radiosondes is also evident at $100 \mathrm{hPa}$ in the tropics. However, the observations degrade the $500 \mathrm{hPa}$ geopotential height (500Z) field in the SH. This appears to be mainly caused by erroneous surface pressure increments in Antarctica. As a result, we have modified the GPS tangent-linear and adjoint routines, prior to the evaluation of the model-level pressures and geopotential heights, in order to remove the sensitivity of the model geopotential height values to the surface pressure. This improves the SH $500 Z$ forecast scores, although a small degradation is still evident at the day 1 and day 2 forecast range.

A simple method for estimating the degrees of freedom for signal (DFS) of a large variational assimilation system is noted and applied to estimate the DFS of the CHAMP measurements assimilated during a 12-hour assimilation window. The CHAMP measurements increase the total DFS of the 4D-Var system by $\sim 4 \%$, and the DFS per CHAMP bending-angle profile is $\sim 34$.

\section{KEYWORDS: 4D-Var Degrees of freedom for signal}

\section{INTRODUCTION}

It is widely recognized that developments in the availability, accuracy and assimilation of satellite data have been significant factors in the recent improvements in the forecast skill of operational numerical weather-prediction (NWP) systems (Simmons and Hollingsworth 2002). Therefore, the possibility of obtaining new satellite measurements which potentially provide information to a higher accuracy or are complementary to the existing observing network is of interest to the operational NWP community. One such new measurement type is Global Positioning System radio occultation (GPSRO, Melbourne et al. 1994). The GPS/MET (Kursinski et al. 1996; Rocken et al. 1997) and CHAMP (Wickert et al. 2001) 'proof-of-principle' experiments demonstrated that the technique can provide high-quality temperature profile information to sub-Kelvin accuracy between heights of 7 and $25 \mathrm{~km}$. The measurements are globally distributed, have an all-weather capability and high vertical resolution. Simulation studies have indicated that GPSRO measurements provide temperature information near the tropopause and in the lower stratosphere of a higher resolution and accuracy than can be derived from advanced infrared sounder measurements (Collard and Healy 2003). Furthermore, from 2006 the GRAS instrument on METOP (Loiselet et al. 2000) and the constellation of six satellites, COSMIC (Constellation Observing System for Meteorology, Ionosphere and Climate; Anthes et al. 2000), will provide a combined total of more than $3000 \dagger$ GPSRO profiles per day in near-real time, so research addressing how to use this data in NWP - and outlining any potential difficulties - is of increasing relevance.

The GPS/MET and CHAMP missions have provided important datasets for research activities directed towards the future operational use of GRAS and COSMIC

\footnotetext{
* Corresponding author: ECMWF, Shinfield Park, Reading RG2 9AX, UK. e-mail: sean.healy@ecmwf.int

$\dagger$ This number includes both rising and setting occultations. The quality and accuracy of rising occultations has yet to be determined.
}

(c) Royal Meteorological Society, 2006. 
measurements, including work on how to assimilate the data. Eyre (1994) and Kuo et al. (2000) outlined a number of possible assimilation strategies for GPSRO data, concluding that the direct assimilation of bending angle is probably preferable to the assimilation of refractivity profiles, which in turn is preferable to assimilating retrievals. All of these approaches have been investigated in recent forecast impact experiments. To briefly summarize, Liu et al. (2001) presented results from an 11-day trial assimilating GPS/MET bending-angle profiles using a ray-tracing forward model in a threedimensional variational (3D-Var) system. Although they claimed a small but consistent improvement in the forecast scores, the results were limited because other satellite data available at that time were not assimilated. It was also recognized that the computational expense of their implementation of the ray tracer made it unsuitable for use within an operational NWP system. Zou et al. (2004) recently presented an improvement of the southern hemisphere (SH) $500 \mathrm{hPa}$ height field as a result of assimilating CHAMP bending-angle profiles. However, these improvements are probably overoptimistic in the context of operational NWP because the $500 \mathrm{hPa}$ height errors in their control experiment are over two times larger than would be obtained with an operational system. Healy et al. (2005) considered the direct assimilation of CHAMP refractivity profiles into the Met Office 3D-Var system and demonstrated a positive impact on stratospheric temperatures in a 16-day trial. The GPSRO measurements improved the forecast fit to radiosondes measurements at $250 \mathrm{hPa}$ in the $\mathrm{SH}$ and globally at $50 \mathrm{hPa}$. They blacklisted the GPSRO data below $4 \mathrm{~km}$ and did not see any significant impact in the troposphere. Poli and Joiner (2003) found no significant forecast impact with the Data Assimilation Office model as a result of assimilating 1D-Var retrievals, assuming they had the same error characteristics as radiosondes.

In this study, we report on the first forecast impact experiments with CHAMP measurements in the European Centre for Medium-range Forecasts (ECMWF) 4D-Var system, using 60 days of CHAMP GPSRO data from 1 August to 29 September 2003. The results represent the first 4D-Var impact experiments over an extended period using the latest set of conventional and satellite observations assimilated operationally, including radiances measurements from the high-resolution Atmospheric Infrared Sounder (AIRS, McNally et al. 2006). The CHAMP data have been assimilated using a one-dimensional (1D) bending-angle observation operator developed by the EUMETSAT Global navigation satellite system Receiver for Atmospheric Sounding satellite application facility (GRAS-SAF). As noted by McNally et al. (2006), it has become increasingly difficult to demonstrate the impact of a single new satellite instrument at ECMWF because of the quality of data that are already assimilated and the redundancy in the combined information provided by different satellite observing systems, so this work represents quite a stringent test for the CHAMP measurements. In section 2 the $1 \mathrm{D}$ bending-angle operator is described, followed by the experimental set-up in section 3 . The forecast experiment results are presented section 4 , where we initially address a degradation of the $500 \mathrm{hPa}$ geopotential height (500Z) field in the $\mathrm{SH}$, then outline the improvements in the upper-tropospheric and lower-stratospheric temperatures and present an estimate of the degrees of freedom for signal (DFS) of the GPSRO observations assimilated during a 12-hour window. The discussion and conclusions are given in section 5 .

\section{THE 1D BENDING-ANGLE OBSERVATION OPERATOR}

The basic physics and preprocessing of the GPSRO measurement have been outlined by a number of authors (e.g. Melbourne et al. 1994; Eyre 1994; Kursinski et al. 1997). The use of bending angles reduces the preprocessing of the GPSRO data prior 
to being passed to the data assimilation system. More specifically, it circumvents the need to perform the 'statistical optimization' (e.g. Hocke 1997) and Abel transform steps. The former introduces climatology model information, whilst the Abel transform broadens the vertical correlation of the observation errors because a refractive index value is a weighted sum of the bending angles. In this study we have implemented a 1D bending-angle observation operator (forward model) in the 4D-Var assimilation system. The bending-angle operator has been developed by the EUMETSAT GRAS-SAF and has been described previously in the context of a 1D-Var retrieval scheme (Marquardt et al. 2005), but it will also be outlined here for the clarity of this paper.

The observation operator evaluates the 'bending angle integral' (e.g. Kursinski et al. 1997) given the observed impact parameter $a$

$$
\alpha(a)=-2 a \int_{a}^{\infty} \frac{\mathrm{d}(\ln n) / \mathrm{d} x}{\left(x^{2}-a^{2}\right)^{1 / 2}} \mathrm{~d} x
$$

where $\alpha$ is the total ionospheric-corrected bending angle, $n$ is the refractive index derived from the model and $x=n r$, where $r$ is the radius value of a point on the ray path. Equation (1) has the opposite sign to Eq. (1) of Kursinski et al., because we adopt the convention that bending towards the earth's surface is positive. The integral is evaluated at the horizontal location of 'the occultation point', defined by Kuo et al. (2004) as the location where the excess phase delay of the GPS signal caused by the atmosphere exceeds $500 \mathrm{~m}$ for the first time. This approximately corresponds to a ray tangent height of 3-4 km above the surface.

The forward model is composed of the following steps. The geopotential heights of the full model levels are evaluated using the standard 4D-Var routines (Simmons and Burridge 1981). The geometric heights of these levels are then calculated with the transform given by List (1984). The radius values are given by adding the radius of curvature, $R_{\mathrm{c}}$, plus the undulation (the height of the geoid above the WGS-84 ellipsoid) to the model geometric height values. The radius of curvature and the undulation values are provided by the data producers, the University Corporation for Atmospheric Research (UCAR). The 'refractivity' values, $N$, are evaluated on the full model levels with

$$
N=10^{6}(n-1)=\frac{c_{1} P}{T}+\frac{c_{2} P_{\mathrm{w}}}{T^{2}},
$$

where $P$ is the total pressure, $P_{\mathrm{w}}$ is the water-vapour pressure and $T$ is the temperature; $c_{1}=77.6 \mathrm{~K}(\mathrm{hPa})^{-1}$ and $c_{2}=3.73 \times 10^{5} \mathrm{~K}^{2}(\mathrm{hPa})^{-1}$ are empirically derived constants (Bean and Dutton 1968). We note that, for a dry atmosphere $\left(P_{\mathrm{w}} \sim 0\right)$, the refractivity is linearly proportional to density.

The refractive index-radius product values, $x=r\left(1+10^{-6} N\right)$, are evaluated on the full levels because this variable is used in the integration of Eq. (1), where it is assumed that the refractivity, $N$, varies exponentially as a function of $x$ between the model levels. Since $10^{-6} N<5 \times 10^{-4}$ we can approximate $(\ln n) \simeq 10^{-6} N$, and the $(\ln n)$ gradient with respect to $x$, between the $i$ th and $(i+1)$ th full model levels, can be written as

$$
\frac{\mathrm{d}(\ln n)}{\mathrm{d} x} \simeq-10^{-6} k_{i} N_{i} \exp \left\{-k_{i}\left(x-x_{i}\right)\right\},
$$

where

$$
k_{i}=\frac{\ln \left(N_{i} / N_{i+1}\right)}{\left(x_{i+1}-x_{i}\right)} .
$$

Note that if $k_{i}=k$ and is assumed to be constant for a profile, the bending-angle integral Eq. (1) has an analytical solution in terms of the modified Bessel function, $K_{0}(k a)$, 
and it is given by $\alpha(a)=2 \times 10^{-6} N(a) \cdot k a$. $\exp (k a) \cdot K_{0}(k a)$ (see Eq. 9.6.23 of Abramowitz and Stegun 1964). This can be useful for testing numerical solutions of Eq. (1).

Equation (1) is simplified further by assuming

$$
\sqrt{x^{2}-a^{2}} \simeq \sqrt{2 a(x-a)}
$$

which is an extremely good approximation near the tangent point, where the ray bending is largest. More generally, the percentage error in $\alpha(a)$ introduced by this assumption is proportional to the refractivity scale height $(1 / k \sim 6 \mathrm{~km})$ divided by the impact parameter $(a \sim 6371 \mathrm{~km})$ and is less than $0.1 \%$. This can be determined by comparing with the analytical modified Bessel function solution. In fact, assuming Eq. (5) is analogous to approximating the modified Bessel function with $K_{0}(k a) \simeq$ $\sqrt{\pi /(2 k a)} \exp (-k a)$, which is the first term of the asymptotic expansion of $K_{0}(k a)$, valid for large $k a$ (see Eq. (9.7.2) of Abramowitz and Stegun 1964).

Substituting Eqs. (3) and (5) into Eq. (1) enables the bending associated with the section of path between the $i$ th and $(i+1)$ th model levels to be written as

$$
\Delta \alpha=10^{-6} \sqrt{2 a} k_{i} N_{i} \exp \left\{k_{i}\left(x_{i}-a\right)\right\} \int_{x_{i}}^{x_{i+1}} \frac{\exp \left\{-k_{i}(x-a)\right\}}{(x-a)^{1 / 2}} \mathrm{~d} x,
$$

which can be integrated to give

$$
\Delta \alpha=10^{-6} \sqrt{2 \pi a k_{i}} N_{i} \exp \left\{k_{i}\left(x_{i}-a\right)\right\}\left[\operatorname{erf}\left\{\sqrt{k_{i}\left(x_{i+1}-a\right)}\right\}-\operatorname{erf}\left\{\sqrt{k_{i}\left(x_{i}-a\right)}\right\}\right],
$$

where erf represents the Gaussian error function. Equation (7) requires $k_{i}$ to be positive and this is ensured by assuming a minimum positive value of $k_{i}^{\min }=1 \times 10^{-6}$. This simplification is reasonable for the current work, but it may need to be re-examined in the future if GPSRO measurements with tangent heights within a few kilometres of the earth's surface are assimilated regularly. The ray bending above the model top $(\sim 65 \mathrm{~km})$ is accounted for by extrapolating the uppermost model parameters. This is done by modifying Eq. (7) when $i+1$ is the uppermost model level and evaluating

$$
\Delta \alpha_{\text {top }}=10^{-6} \sqrt{2 \pi a k_{i}} N_{i} \exp \left\{k_{i}\left(x_{i}-a\right)\right\}\left[1-\operatorname{erf}\left\{\sqrt{k_{i}\left(x_{i}-a\right)}\right\}\right] .
$$

Note that, for a bending angle with tangent height near $45 \mathrm{~km}$, the total ionosphericcorrected bending for the section of ray path above the top of the ECMWF model $(0.1 \mathrm{hPa} \sim 65 \mathrm{~km})$ is only of order $1 \times 10^{-6}$ radians, which is smaller than the assumed observation errors (see section 3(b)). Furthermore, since the ECMWF model will soon be extended to $0.01 \mathrm{hPa}$, the extrapolation above the model top is not seen as a significant forward model error term.

\section{EXPERIMENTAL SET-UP}

\section{(a) The NWP system}

The forecast impact experiments are performed with the CY26R3 version of the ECMWF forecast/assimilation system. The NWP forecast model is run at T319 horizontal resolution $(\simeq 62.5 \mathrm{~km})$ and has 60 levels in the vertical, up to $0.1 \mathrm{hPa}$. The analyses are produced with ECMWF's incremental 4D-Var system (Rabier et al. 2000; Klinker et al. 2000$)$ at $\mathrm{T} 159(\simeq 125 \mathrm{~km})$ with a 12-hour assimilation window. In the 'control' experiment (CTL), the operational set of conventional and satellite observations are assimilated, including radiances measured by AIRS (McNally et al. 2006). The CHAMP experiments are identical except that the CHAMP bending-angle profiles are assimilated in addition to those observations used in the control. 


\section{(b) Observed bending angles}

The experiments use 60 days of CHAMP ionospheric bending angles from 1 August to 29 September 2003, processed by UCAR. A full description of the UCAR processing is given by Kuo et al. (2004), but we note that they have implemented the Full Spectral Inversion (FSI) method (Jensen et al. 2003). CHAMP typically provides $\sim 160$ bendingangle profiles per day. The profiles provided by UCAR have a high sampling rate in the vertical, providing of order 2500 bending-angle values. The information content of a profile does not justify assimilating this number of measurements and the bendingangle errors are almost certainly highly correlated at this sampling rate. Hence, the 'raw' bending angles are interpolated and thinned onto a set of fixed 'impact heights', $h$, where $h$ is defined as the impact parameter minus the local radius of curvature, (i.e. $h=a-R_{\mathrm{c}}$ ). We use 180 fixed impact-height levels between the surface and $\sim 40 \mathrm{~km}$. The vertical spacing of the bending angles is typically $\sim 120 \mathrm{~m}$ near the surface increasing with height to $\sim 300 \mathrm{~m}$ near $40 \mathrm{~km}$. The interpolation onto the fixed impact heights is unlikely to introduce any additional vertical correlations in the errors, because the UCAR bending angles are given at a much higher vertical sampling rate. Note that all bending angles with impact heights of less than $5 \mathrm{~km}$ are 'blacklisted', meaning they are not used by the $4 \mathrm{D}$-Var assimilation system to calculate the analysis. This conservative approach is adopted because the GPSRO bending angles are biased low near the surface (Rocken et al. 1997; Ao et al. 2003) and it limits the possibility of deriving humidity information from the GPSRO observations because the humidity information content is highest for ray paths that are close to the surface.

Currently, a single combined observation plus forward model error covariance matrix is used globally. The standard deviations of the combined errors are assumed to vary with impact height, $h$. The percentage error is assumed to be $10 \%$ of the observed value at $h=0$, falling linearly with $h$ to $1 \%$ at $h=10 \mathrm{~km}$. Above $10 \mathrm{~km}$, the error is assumed to be $1 \%$ of the observed value until this reaches a lower limit of $6 \times 10^{-6}$ radians. The percentage error is larger near the surface because of the observation/forward model error caused by horizontal gradients. The $6 \times 10^{-6}$ radians lower limit is estimated from an off-line calculation of the statistics of the observed minus forecast bending-angle differences above $40 \mathrm{~km}$. The differences above $40 \mathrm{~km}$ are expected to be largely a result of the observation errors. Vertical correlations of the errors are not included, so the observation-error covariance matrix, $\mathbf{R}$, is assumed to be diagonal. (Diagonal $\mathbf{R}$ matrices are currently assumed for all observation types at ECMWF.) The diagnostics of the 4D-Var system suggest that the error estimates are reasonable. For the experiments presented in this study, the GPSRO contribution to the total observation cost function value at the analysis state, $\mathbf{x}_{\mathrm{a}}$, divided by the number, $m$, of GPSRO bending angles that have been assimilated is typically

$$
\frac{1}{m}\left\{\mathbf{y}^{\mathrm{o}}-H\left(\mathbf{x}_{\mathrm{a}}\right)\right\}^{\mathrm{T}} \mathbf{R}^{-\mathbf{1}}\left\{\mathbf{y}^{\mathrm{o}}-H\left(\mathbf{x}_{\mathrm{a}}\right)\right\} \sim 1.5,
$$

where $\mathbf{y}^{0}$ is a vector containing the bending-angle observations and $H$ is the bendingangle observation operator. Ideally, this number should be close to unity if the error estimates are realistic.

The GPSRO measurements have been integrated into both the first-guess departure (Järvinen and Undén 1997) and the variational (Andersson and Järvinen 1999) qualitycontrol (QC) procedures used in the 4D-Var system. After QC and blacklisting impact heights below $5 \mathrm{~km}$, CHAMP provides $\sim 80$ profiles containing 12500 bending angles per 12-hour assimilation window. For comparison we note that, after QC and blacklisting, the total number of other observations assimilated is typically around 2.7 million, 


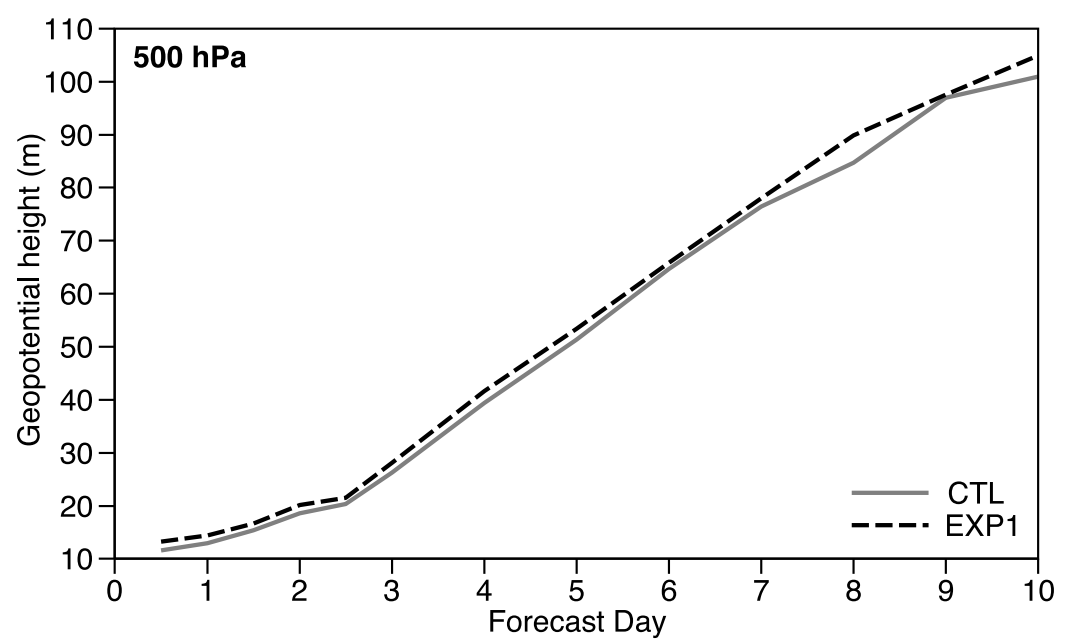

Figure 1. The r.m.s. fit to radiosonde 500Z measurements in the southern hemisphere as a function of forecast range for the CTL (solid) and EXP1 (dashed) experiments, averaged over 1-31 August 2003 (31 cases at 12 UTC).

so the CHAMP bending angles increase the total number of observations assimilated per cycle by around $0.5 \%$. The additional 12500 bending angles increase the $4 \mathrm{D}$-Var central processing unit time by around $2 \%$.

\section{RESULTS}

\section{(a) EXP1: Including surface pressure increments}

The first experiment (EXP1) assimilates CHAMP data for the period 1-31 August 2003. Although the CHAMP measurements produce a clear and statistically significant positive improvement in the upper-tropospheric and lower-stratospheric temperatures (essentially the same as the improvements described in section 4(b)), they degrade the $500 \mathrm{Z}$ values in the $\mathrm{SH}$. Figure 1 illustrates the r.m.s. fit to $500 \mathrm{Z}$ observations in the $\mathrm{SH}$ for the CTL and EXP1 experiments. The degradation at days 1 and 2 is statistically significant at the $0.1 \%$ level with the Student ' $t$ ' test. Similar results for $500 \mathrm{Z}$ are obtained when the experiments are verified against both the operational and their own analyses.

These results appear less impressive than those presented recently by Zou et al. (2004), but note that both the CTL and EXP1 errors in Fig. 1 are considerably smaller than in Fig. 9a of Zou et al., which are larger than would be expected with an operational NWP system. In EXP1 we find that the CHAMP measurements degrade the day 1 forecast error of the $500 \mathrm{Z}$ field to $\simeq 15 \mathrm{~m}$, whereas their GPS experiment $500 \mathrm{Z}$ error is greater than $20 \mathrm{~m}$.

The degradation of the $500 \mathrm{Z}$ is primarily over Antarctica and appears to be largely a result of surface pressure, $P_{\mathrm{S}}$, increments introduced by the GPSRO measurements. The r.m.s. of the (EXP1 - CTL) $P_{\mathrm{S}}$ analysis differences are shown in Fig. 2. In theory, surface pressure information can be derived from GPSRO measurements (Healy and Eyre 2000) because the ray bending is related to the vertical gradient of refractivity, and in turn the vertical gradient of density. The measurements have a height-based vertical coordinate, meaning that $P_{\mathrm{s}}$ is required in the forward model for the integration of the hydrostatic relationship used to evaluate the height of the model levels, 


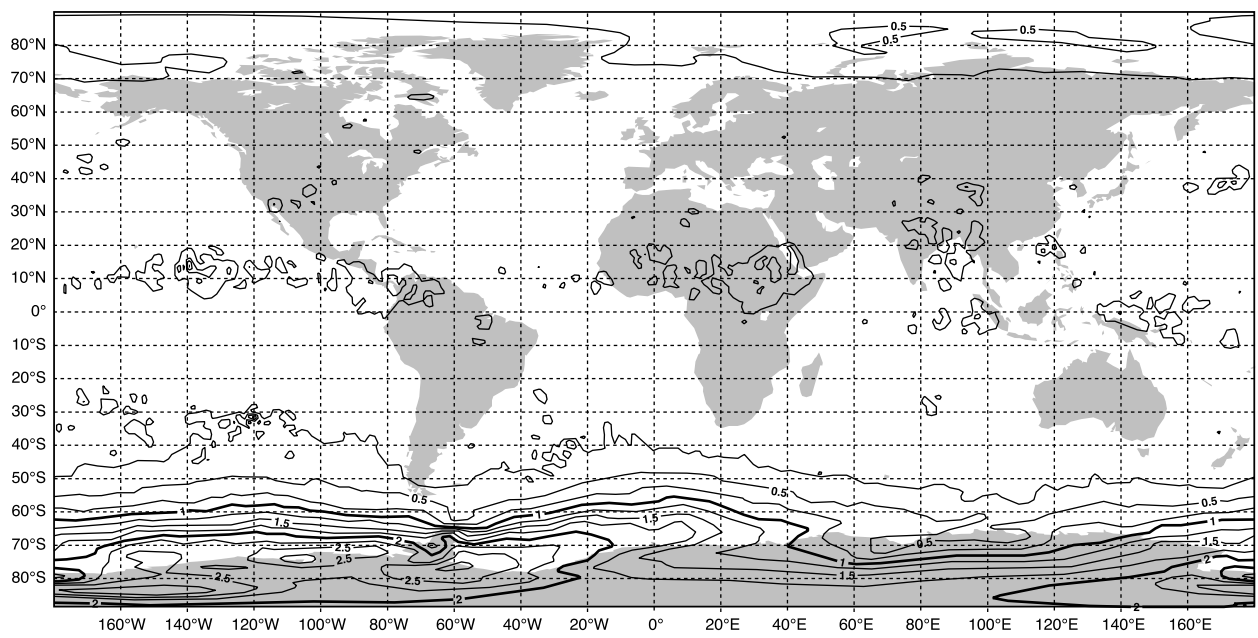

Figure 2. The r.m.s. differences in the surface pressure analyses of the EXP1 and CTL experiments, averaged over 1-31 August 2003. The contour interval is $0.25 \mathrm{hPa}$.

as described in section 2. Adjusting the $P_{\mathrm{s}}$ values during the assimilation changes the fit to the observed bending angles by effectively moving the entire simulated profile up or down. However, deriving surface pressure information from GPSRO measurements has proved difficult in practice (e.g. Poli et al. 2002). We believe the $P_{\mathrm{s}}$ information derived from the measurements is probably overestimated in this study as a result of neglecting vertical correlations in the observation and forward model errors. This approximation effectively assumes a profile of indirect measurements of surface pressure with uncorrelated errors and it leads to an unrealistically small estimated error in $P_{\mathrm{s}}$. In 1D-Var retrieval experiments, we have found that the magnitude of the $P_{\mathrm{s}}$ increments is reduced when a full covariance matrix is used in the calculation. Vertically correlated errors will usually arise in the pre-processing of the measurement. For example, the correlations introduced by the FSI technique, which has been implemented by UCAR, have yet to be investigated; horizontal gradient errors, uncertainties in the radius of curvature values or the geopotential-geometric height transform are also potential sources of vertically correlated error. On the other hand, the $P_{\mathrm{s}}$ information content of a measured bending angle is related to the height of its tangent point above the surface, so ordinarily blacklisting impact heights below $5 \mathrm{~km}$ limits the magnitude of the increments. However, the exception is over high orography, where the measurements can reach close to the surface despite the blacklisting. This appears to be the case over Antarctica, where there is a combination of orography and relatively high GPSRO data density. We do not have similar problems over other high plateaux, such as Greenland and Asia, because the analysis is constrained more tightly by other observations.

\section{(b) EXP2: Removal of surface pressure increments}

In the second experiment (EXP2) the GPSRO tangent-linear and adjoint codes have been modified before the calculation of pressure on the model levels and the subsequent hydrostatic integration routines, in order to remove the sensitivity of the model-level height values to $P_{\mathrm{s}}$. This approach is potentially problematic because it can result in realistic $P_{\mathrm{s}}$ increments being aliased into other variables, but we have found that it significantly improves the SH 500Z results, as illustrated in Fig. 3 for a 60-day period 


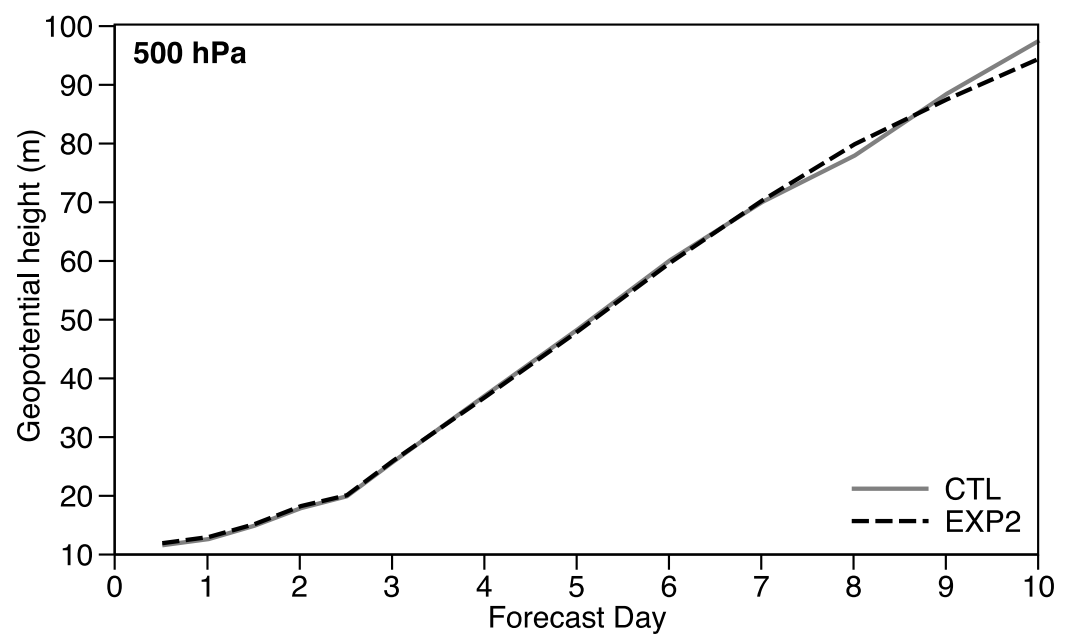

Figure 3. As Fig. 1, but for the CTL (solid) and EXP2 (dashed) experiments, averaged over 1 August29 September 2003 (60 cases at 12 UTC).

from 1 August to 29 September 2003. (The improvement would be the same if we only plotted the statistics for the first 31 days used in EXP1.) However, although the major source of additional error has clearly been removed, there remains a small degradation of the fit at the day 1 and day 2 forecast ranges. The differences are statistically significant at the $0.1 \%$ and $2 \%$ levels for days 1 and 2, respectively, when calculated with the Student ' $t$ ' test. We also obtain similar statistically significant results for the day 1 and day 2 forecast ranges, when the forecasts are verified against their own analyses. The $500 Z$ forecast anomaly correlations for CTL and EXP2 are shown in Fig. 4. Note that the statistics only include 50 cases - rather than the 60 used when verifying against observations - because the forecasts are verified against their own analyses. The slight degradation of EXP2 from days 6 to 8 is not statistically significant at the $10 \%$ level, so the results are considered neutral with this forecast score. Figure 4 can be compared with Fig. 10b of Zou et al. (2004). Note that the skill of a 7-day forecast from CTL or EXP2 is equivalent to that of a 5-day forecast with their control or experiment. To summarize, removing the $P_{\mathrm{S}}$ increments clearly removes a large component of the increased error in the SH 500Z, but there is still some degradation of the short-range forecasts. It is not yet clear why this is the case, given that the data with impact heights below $5 \mathrm{~km}$ are blacklisted; it may be an inherent limitation of a 1D operator combined with poorly specified errors/correlations near the surface, but further work is required to explore these issues.

The GPSRO measurements appear to provide useful temperature information in the upper troposphere and lower stratosphere. We have observed that the GPSRO measurements can introduce sharp 1-2 K increments around $200 \mathrm{hPa}$ at the observation location. More generally, the zonally averaged mean and r.m.s. (EXP2 - CTL) analysis differences are shown in Fig. 5. Despite the low number of CHAMP observations, it is clear that they are producing significant differences in the temperature analyses. The r.m.s. differences are largest in the lower stratosphere where the GPSRO information content is expected to be highest, and tend to be larger in the tropics (TR) and $\mathrm{SH}$ than in the northern hemisphere $(\mathrm{NH})$. The GPSRO measurements change the mean analyses around the tropical tropopause and near both poles, particularly 


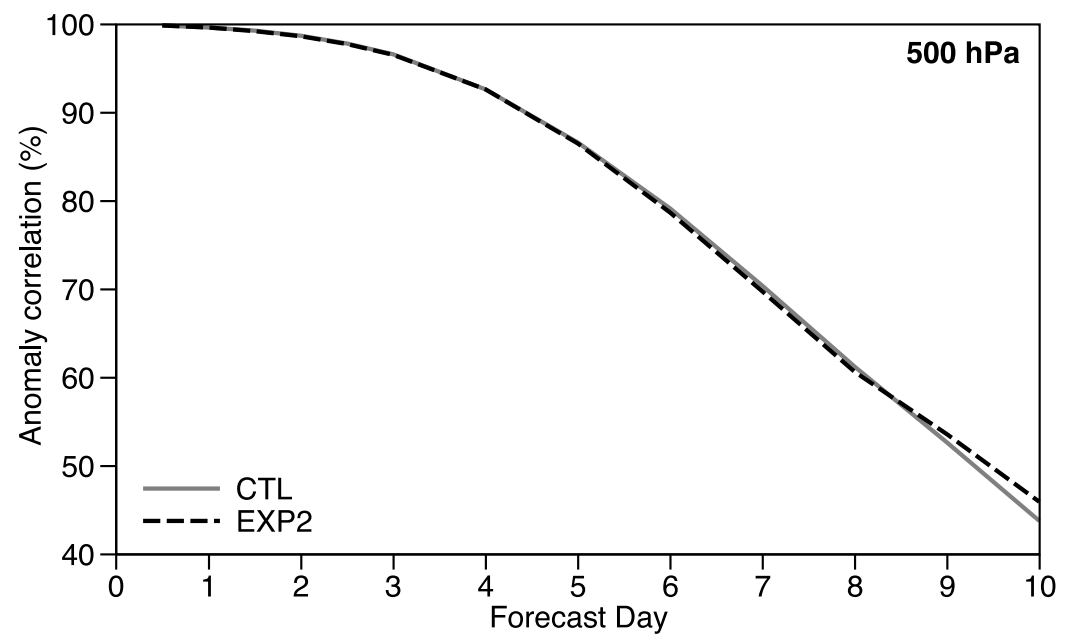

Figure 4. The anomaly correlation for southern hemisphere 500Z for the CTL (solid) and EXP2 (dashed) experiments ( 50 cases at 12 UTC).

the winter pole (Antarctica). The ECMWF model is biased cold at $100 \mathrm{hPa}$ in the tropics and GPSRO observations are found to increase the temperature in this region by $\sim 0.2 \mathrm{~K}$. Over Antarctica, the mean differences have an oscillatory structure in the vertical. It is also interesting to note that, despite the clear differences in the mean analyses over Antarctica, the mean CTL and EXP2 analysis increments (i.e. analysis minus forecast differences) averaged over the full 60-day period are quite similar. In fact, the analysis increments over Antarctica only differ markedly during the first two days of the experiment, but the resulting analysis differences appear to be retained throughout the remainder of the experiment, suggesting that the first set of GPSRO measurements correct some systematic errors.

Figure 6 shows that GPSRO data improve both the background and the analysis fit to radiosondes in Antarctica that have been used in the experiments. The results clearly illustrate that the GPSRO measurements are providing information that is consistent with the radiosondes in this region, improving both the mean and standard deviation of the analysis and 12-hour forecast fit from around $300 \mathrm{hPa}$ to $50 \mathrm{hPa}$. Furthermore, assimilating the GPSRO bending angles reduces the number of stratospheric radiosonde temperature measurements in Antarctica that are rejected during the assimilation. The results suggest that the mean analysis differences introduced by the GPSRO observations shown in Fig. 5 are accurate. For example, in Fig. 5 the mean EXP2 analysis is $\sim 0.4 \mathrm{~K}$ cooler than the CTL at $150 \mathrm{hPa}$ over Antarctica. From Fig. 6 it is apparent that this reduces a negative bias in the radiosonde-analysis departures. We note that the sharp vertical structure in the mean stratospheric temperature differences over the winter pole is a well-known problem thought to be related to inconsistencies in the approach to the bias correction of Advanced Microwave Sounding Unit A (AMSU-A) and AIRS measurements (Graeme Kelly 2004, personal communication). It is expected that these problems will be reduced as a result of a new bias-correction model for AMSU-A which has recently been introduced operationally. Nevertheless, it is extremely encouraging that the GPSRO observations partially correct these errors and it emphasizes the potential usefulness of independent, high-quality observations that do not require bias correction. 

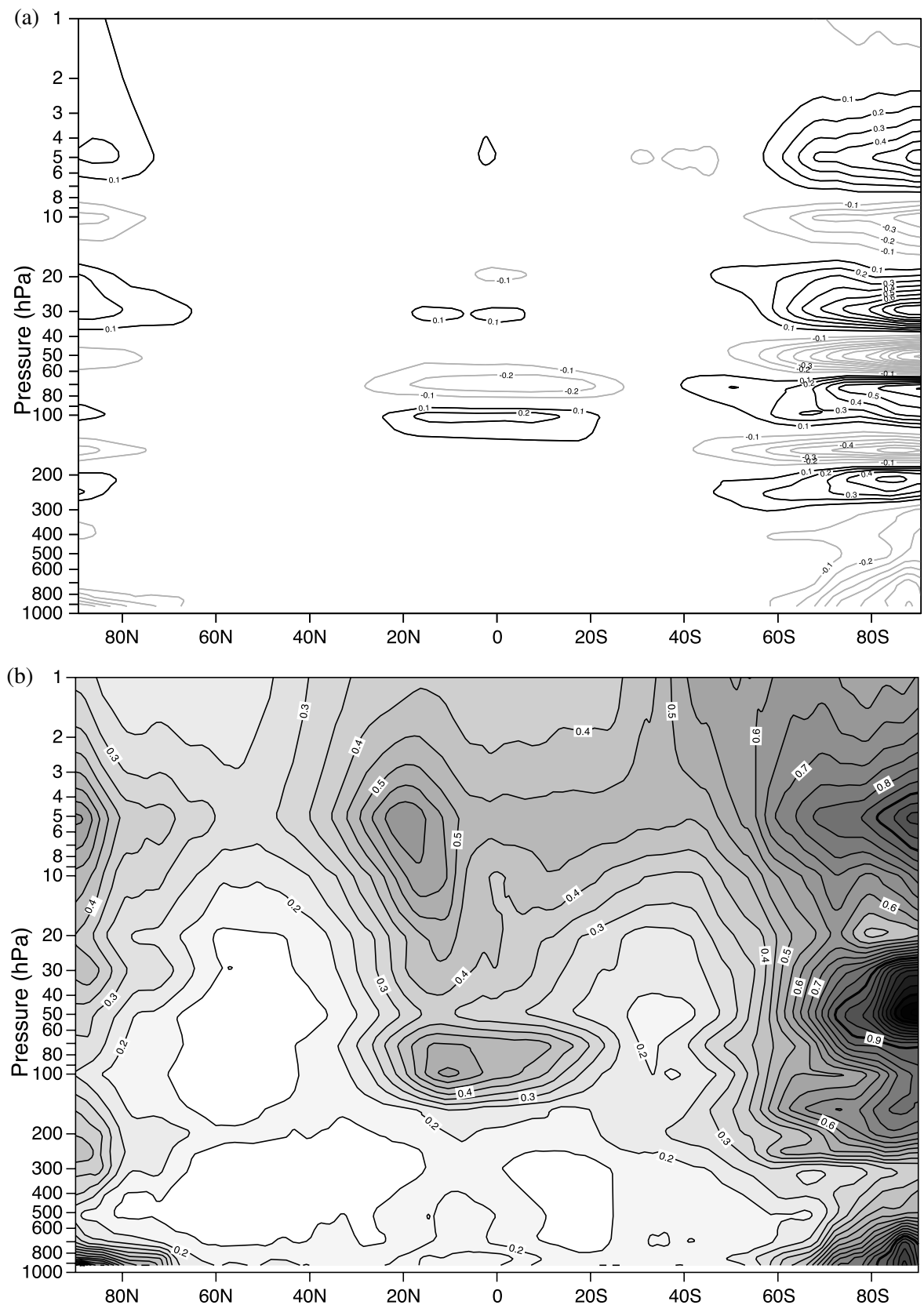

Figure 5. The zonally averaged (a) mean and (b) r.m.s. EXP2 minus CTL temperature analysis differences as a function of pressure, averaged over the period 1 August-29 September 2003 . The contour interval is (a) $0.1 \mathrm{~K}$ and (b) $0.05 \mathrm{~K}$.

Assimilating the GPSRO measurements improves the r.m.s. fit to radiosonde temperature measurements in the $\mathrm{SH}$ upper troposphere and lower stratosphere over the day 1 to day 5 forecast range, as illustrated in Fig. 7. The r.m.s. values do not increase smoothly as a function of forecast day because of the differences in radiosonde coverage at 00 and 12 UTC. The improvements introduced by the GPSRO measurements may appear small, but they are statistically significant. Table 1 provides the statistical 

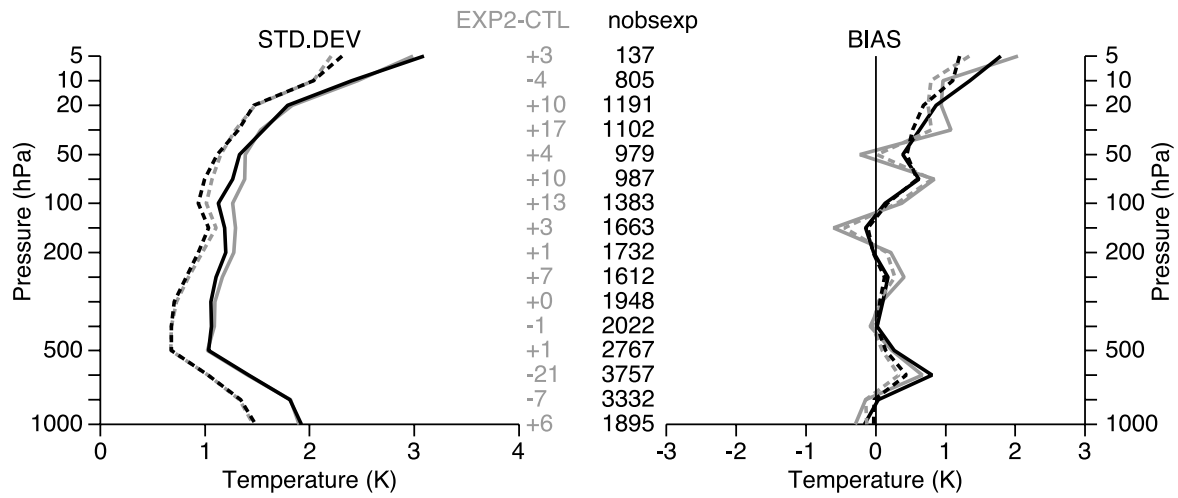

Figure 6. The standard deviation and bias of the 12-hour forecast (solid) and analysis (dashed) fits to radiosondes (radiosonde minus NWP) in Antarctica, calculated for the CTL (grey) and EXP2 (black) experiments. The central columns give, for each pressure level, the number of comparisons (black) and the number of additional measurements used in EXP2 (grey).

(a)

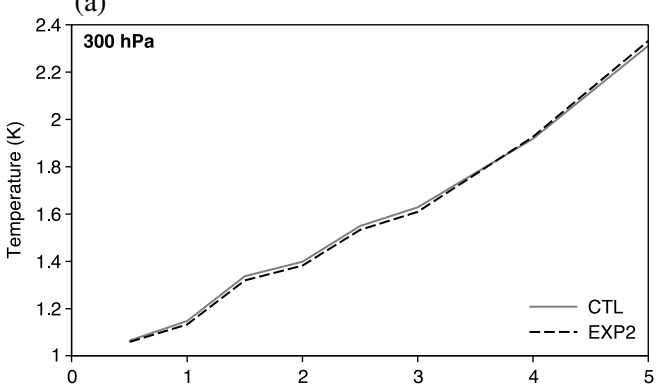

(c)

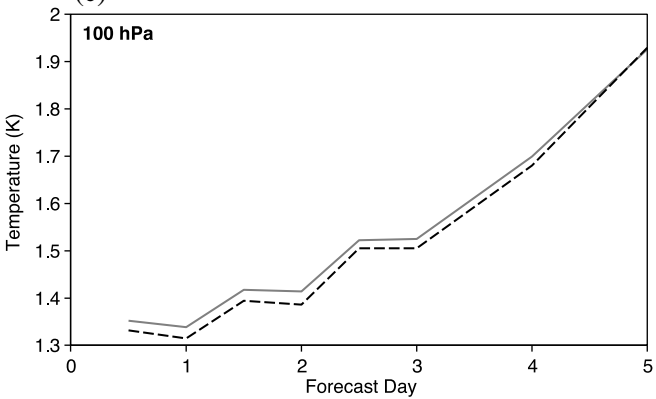

(b)

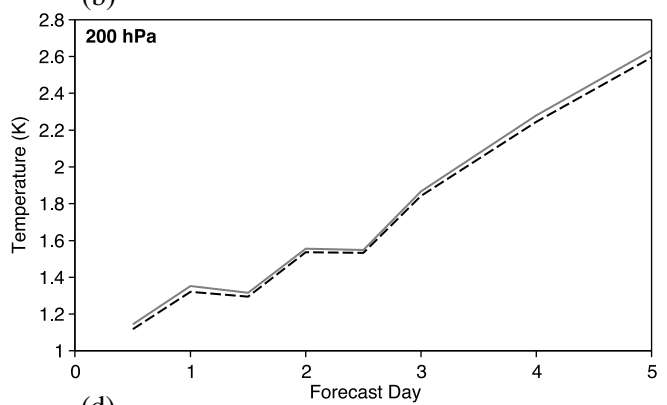

(d)

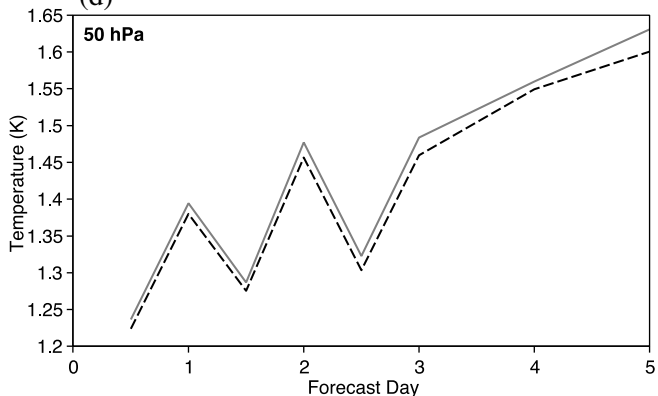

Figure 7. The r.m.s. fit to radiosonde temperatures at 300, 200, 100 and $50 \mathrm{hPa}$ in the southern hemisphere for the CTL (solid) and EXP2 (dashed) forecast experiments. The statistics are based on 60 days of data.

significance of the change in r.m.s. fit to radiosondes. The values are calculated with the Student ' $\mathrm{t}$ ' test and a tabulated value ' $y$ ' means that the result is significant at the $y \%$ level. It should be emphasized that the GPSRO observations and radiosondes are not generally collocated. The improvements at the radiosonde locations come about through the NWP system propagating the GPSRO information spatially and temporally. We also note that improvements in the temperatures are also found when verifying forecasts against their own analyses (figure not shown). These results are broadly consistent with those found with the Met Office 3D-Var assimilation system (Healy et al. 2005). 
TABLE 1. THE STATISTICAL SIGNIFICANCE (\%) OF THE CHANGE IN R.M.S. FIT TO RADIOSONDE TEMPERATURE VALUES AT FOUR PRESSURE LEVELS (hPa) DUE TO ASSIMILATION OF GPSRO DATA

\begin{tabular}{|c|c|c|c|c|c|c|c|c|c|c|c|c|}
\hline \multirow[b]{2}{*}{ Forecast day } & \multicolumn{4}{|c|}{ Northern hemisphere } & \multicolumn{4}{|c|}{ Tropics } & \multicolumn{4}{|c|}{ Southern hemisphere } \\
\hline & 300 & 200 & 100 & 50 & 300 & 200 & 100 & 50 & 300 & 200 & 100 & 50 \\
\hline 1 & - & 1.0 & 0.5 & - & -2.0 & 2.0 & 0.1 & -10.0 & 1.0 & 0.1 & 0.1 & 5.0 \\
\hline 2 & 10.0 & - & 0.5 & - & - & 1.0 & 0.1 & - & 2.0 & 0.5 & 0.1 & 0.2 \\
\hline 3 & - & - & 10.0 & - & - & - & 0.1 & 10.0 & 2.0 & 1.0 & 0.5 & 0.1 \\
\hline 4 & - & - & - & - & - & - & 2.0 & - & - & 2.0 & 2.0 & 10.0 \\
\hline 5 & - & - & - & - & - & - & 1.0 & 0.2 & - & 10.0 & - & 0.2 \\
\hline
\end{tabular}

A negative value indicates that the r.m.s. fit is degraded at this level.

Only values $\leq 10 \%$ are considered significant. Values $>10 \%$ are shown as '-'.
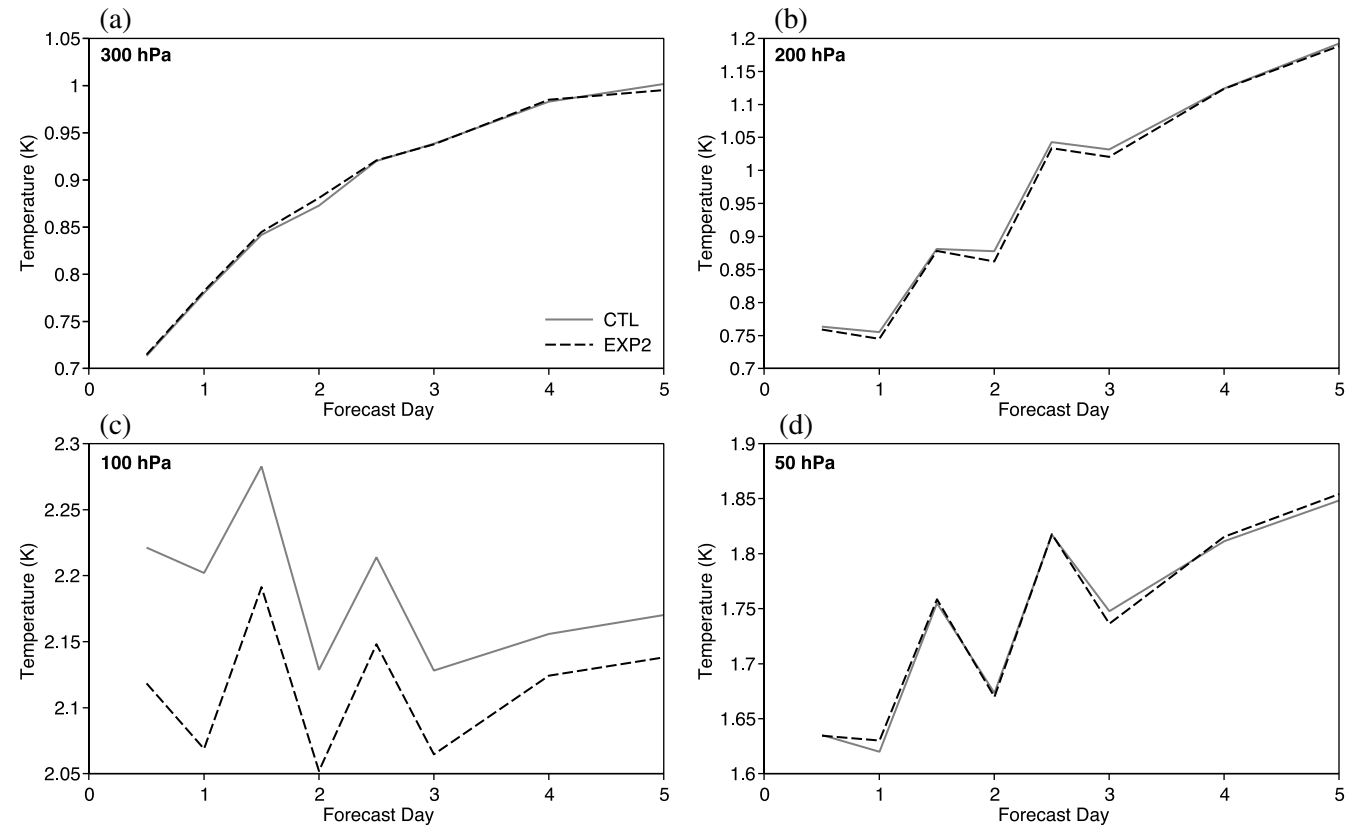

Figure 8. As Fig. 7, but for the tropics.

The r.m.s. fit of the forecasts to radiosonde measurements in the TR is shown in Fig. 8 and the confidence levels are given in Table 1 . The results are particularly good at $100 \mathrm{hPa}$ where the r.m.s. difference for a 24 -hour forecast is reduced by over $\sim 0.1 \mathrm{~K}$. This is encouraging because the assimilation GPSRO measurements resulted in quite large (EXP2 - CTL) analysis differences $(\sim 0.5 \mathrm{~K})$ near $100 \mathrm{hPa}$ in the TR (Fig. 5). The results for the $\mathrm{NH}$ are shown in Fig. 9 and Table 1. We see very little improvement between $300 \mathrm{hPa}$ and $50 \mathrm{hPa}$ in the NH, consistent with the fact that the (EXP2 - CTL) analysis differences are smallest here (Fig. 5). However, the r.m.s. fit does appear to be improved slightly at the $100 \mathrm{hPa}$ level.

We have investigated the statistics of the background and analysis bending-angle departures, $\mathbf{y}^{\mathrm{o}}-H\left(\mathbf{x}_{\mathrm{b}}\right)$ and $\mathbf{y}^{\mathrm{o}}-H\left(\mathbf{x}_{\mathrm{a}}\right)$, respectively. Generally the $\mathrm{O}-\mathrm{B}$ and $\mathrm{O}-\mathrm{A}$ distributions are broader in the tropical lower stratosphere than in the $\mathrm{NH}$ and $\mathrm{SH}$, as illustrated in Fig. 10. This shows the distribution of bending-angle departures with impact heights between 17.5 and $19.5 \mathrm{~km}$, corresponding to tangent heights of $\sim 17.3$ and $19.3 \mathrm{~km}$. (Note that the vertical axis changes in the three plots, but we are interested 
(a)
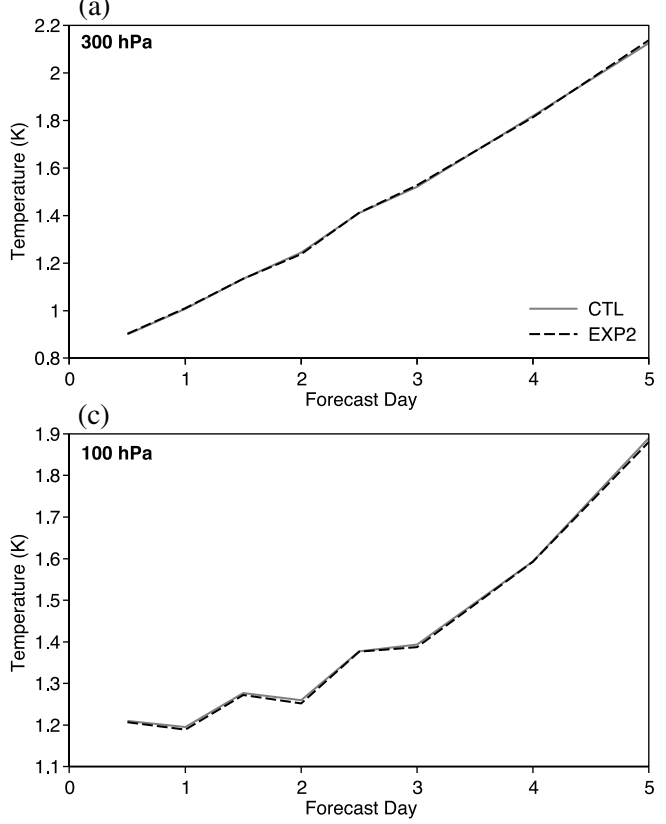

(b)

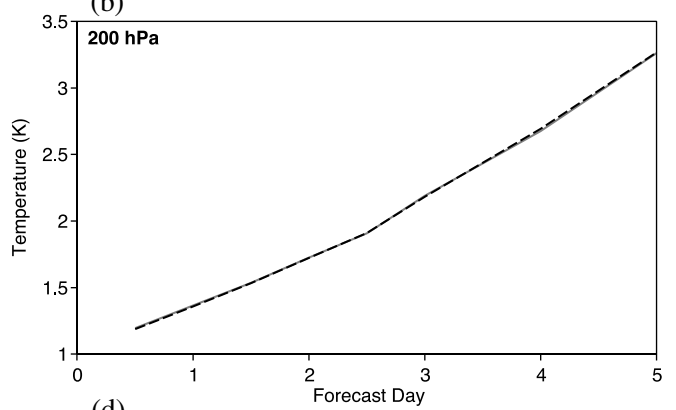

(d)

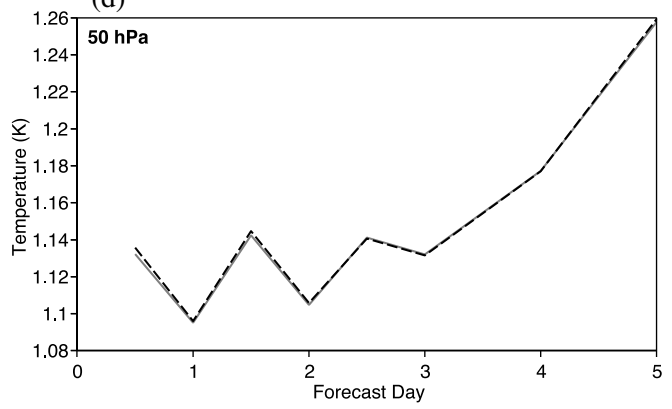

Figure 9. As Fig. 7, but for the northern hemisphere.

in the shape and width of distributions here.) The statistics (Table 2) use data that have passed the screening (Järvinen and Undén 1997) and variational QC (Andersson and Järvinen 1999) steps, meaning that data with O-A departures greater than 5 times the assumed observation error have been removed. As expected, the analysis departures are smaller than the background departures as a result of the 4D-Var minimization. The standard deviation of TR distributions are twice those seen in the NH and SH distributions. This is most likely a result of larger bending-angle representation error in the TR. It has been shown that the high vertical resolution of the GPSRO measurements make them useful in the study of gravity waves (Tsuda et al. 2000). We believe the broader distributions in the TR simply reflect the fact that the GPSRO measurements contain gravity-wave information which cannot be represented by the NWP model. This interpretation is consistent with the $\mathrm{O}-\mathrm{B}$ and $\mathrm{O}-\mathrm{A}$ fits to radiosonde temperature measurements between 100 and $30 \mathrm{hPa}$. In general, the standard deviation of the $\mathrm{O}-\mathrm{A}$ fit to the radiosonde temperature measurements between 100 and $30 \mathrm{hPa}$ in the tropics is $\sim 2 \mathrm{~K}$, whereas it is closer to $\sim 1.5 \mathrm{~K}$ and $\sim 1.7 \mathrm{~K}$ in the $\mathrm{NH}$ and $\mathrm{SH}$, respectively. Therefore, it seems reasonable to conclude that differences in the bendingangle distributions are arising as a result of a model limitation, rather than a problem with the measurements. Figure 10 also suggests that we should employ an $\mathbf{R}$ matrix with latitudinally varying error variances, to reduce the weight given to the bending angles in this region, until we can make use of this information.

The biases in the $\mathrm{NH}$ and $\mathrm{SH}$ distributions are also of interest. The background $\mathrm{O}-\mathrm{B}$ departures in the $\mathrm{NH}$ and $\mathrm{SH}$ appear to be biased negative by around $1-3 \times 10^{-4}$ radians for tangent heights between 10 and $20 \mathrm{~km}$. The biases are not constant with height. In fact, in the $\mathrm{NH}$ and $\mathrm{SH}$ the departures of bending angles just above the blacklisting cutoff have a positive bias of $1 \times 10^{-4}$ radians. Bending angles with tangent heights near $40 \mathrm{~km}$ have a small negative bias of $-1 \times 10^{-6}$ radians. (At $40 \mathrm{~km}$, the observation 
(a)

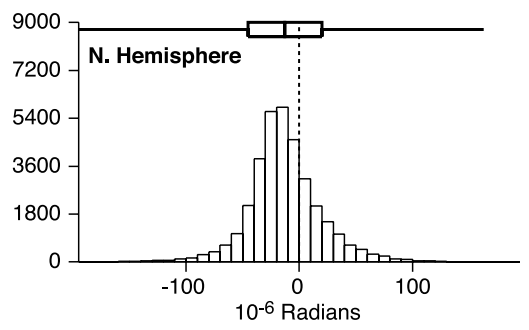

(c)

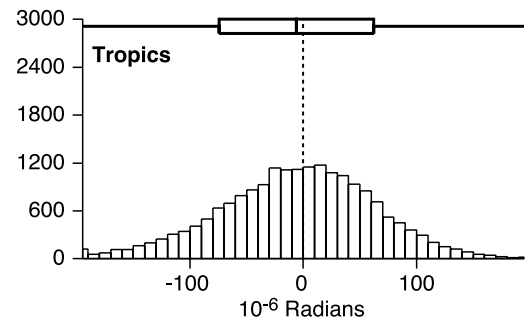

(e)

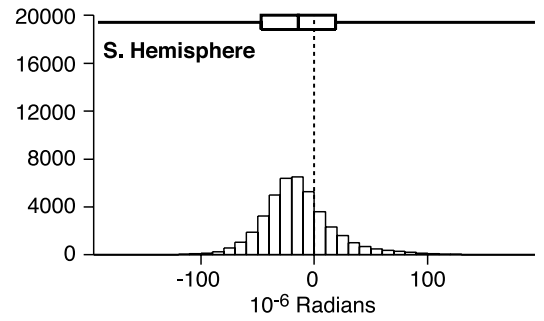

(b)

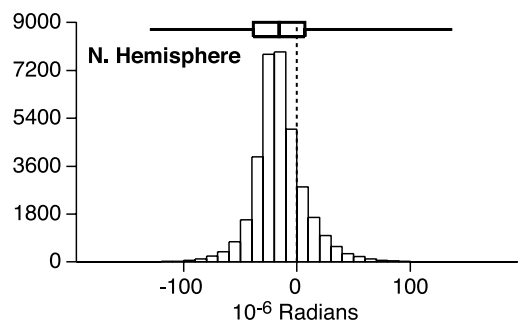

(d)

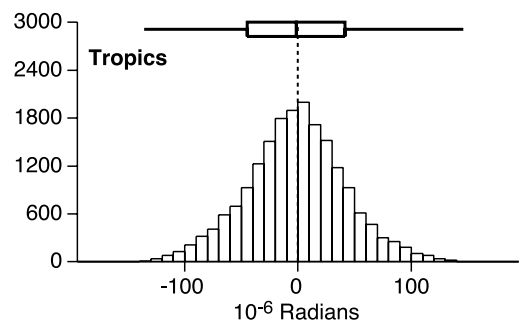

(f)

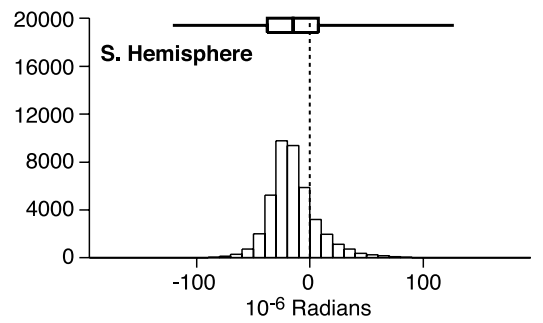

Figure 10. The (a) background and (b) analysis departures in bending angle for the northern hemisphere for impact heights between 17.5 and $19.5 \mathrm{~km}$. (c, d) and (e, f) are as (a, b) but for the tropics and southern hemisphere, respectively. The box and line plots show \pm s.d. and $\max / \mathrm{min}$ values. Detailed statistics are given in Table 2 .

TABLE 2. STATISTICS OF BACKGROUND AND ANALYSIS DEPARTURES IN BENDING ANGLE $\left(10^{-4}\right.$ radians) FOR IMPACT HEIGHTS BETWEEN 17.5 AND $19.5 \mathrm{KM}$

\begin{tabular}{lcclccccc}
\hline & \multicolumn{2}{c}{ Northern hemisphere } & & \multicolumn{2}{c}{ Tropics } & & \multicolumn{2}{c}{ Southern hemisphere } \\
\cline { 2 - 3 } \cline { 8 - 8 } & Background & Analysis & & Background & Analysis & & Background & Analysis \\
\hline Number & 34687 & 34687 & & 19243 & 19243 & & 41573 & 41573 \\
Mean & -0.127 & -0.157 & & -0.602 & -0.162 & & -0.141 & -0.151 \\
R.m.s. & 0.350 & 0.276 & & 0.685 & 0.433 & & 0.358 & 0.272 \\
St.dev. & 0.326 & 0.227 & & 0.682 & 0.433 & & 0.329 & 0.226 \\
Min & -2.27 & -1.30 & & -2.64 & -1.36 & & -1.91 & -1.21 \\
Max & 1.63 & 1.37 & & 2.40 & 1.46 & & 2.62 & 1.27 \\
\hline
\end{tabular}


errors are assumed to be $6 \times 10^{-6}$ radians.) The fact that the biases are small for tangent heights around $40 \mathrm{~km}$ indicates that those found between 10 and $20 \mathrm{~km}$ are not caused by either the ionospheric correction of the observations or the extrapolation used in the forward model (Eq. (8)). Furthermore, since GPSRO measurements are tending to improve the fit to radiosondes in the lower stratosphere, it suggests that the biases are a result of the NWP model rather than the observations.

\section{(c) Degrees of freedom for signal of GPSRO measurements}

The DFS is widely used in satellite meteorology to estimate the information content' of observations (Rodgers 2000). More recently it has been used as a diagnostic for large variational assimilation systems (Fisher 2003; Cardinali et al. 2004). The DFS is a scalar value which can be interpreted as the number of state vector elements that are well measured. It can be evaluated with the matrix expression DFS $=\operatorname{Tr}\left(\mathbf{I}-\mathbf{A B}^{-1}\right)$, where $\operatorname{Tr}$ denotes the matrix trace and $\mathbf{I}, \mathbf{B}$ and $\mathbf{A}$ are the identity, background-error covariance and analysis-error covariance matrices, respectively. Calculation of the DFS in this form is relatively straightforward for $1 \mathrm{D}$ satellite retrieval problems because the matrices are of a reasonable size and can manipulated easily. This is not the case when estimating the DFS of a large 3D- or 4D-Var assimilation system, so Fisher (2003) has applied quite sophisticated numerical methods for calculating the trace of functions of large matrices to the problem. However, if a forecast impact experiment has been performed, a simple alternative approach is to estimate the DFS from the time series of the $3 \mathrm{D}$ - or $4 \mathrm{D}$-Var background penalty term values, $J_{\mathrm{b}}$, evaluated at the analysis state, because in the linear limit (see Eq. (2.46) in Rodgers 2000)

$$
\operatorname{Tr}\left(\mathbf{I}-\mathbf{A} \mathbf{B}^{-1}\right)=\overline{\left(\mathbf{x}_{\mathrm{a}}-\mathbf{x}_{\mathrm{b}}\right)^{\mathrm{T}} \mathbf{B}^{-1}\left(\mathbf{x}_{\mathrm{a}}-\mathbf{x}_{\mathrm{b}}\right)}
$$

where the overbar denotes the expectation value, and $\mathbf{x}_{\mathrm{b}}$ and $\mathbf{x}_{\mathrm{a}}$ are the background and analysis states, respectively. We have used this approach to calculate the DFS of the GPSRO observations from the time series of the 120 (EXP2-CTL) $J_{\mathrm{b}}$ differences. The DFS of CTL is DFS $\mathrm{CTL}=66110 \pm 321$ and of EXP2 is DFS $\mathrm{EXP}_{2}=68811 \pm 324$. These are consistent with the values derived by Fisher (2003). The DFS associated with the CHAMP observations is evaluated by subtracting the CTL value from the EXP2 and is $\mathrm{DFS}_{\mathrm{RO}}=2700 \pm 64$, which is $4 \%$ of the $\mathrm{DFS}_{\mathrm{EXP} 2}$ value. The $\mathrm{DFS}_{\mathrm{RO}}$ per profile is $34(=2700 / 80)$, and the $\mathrm{DFS}_{\mathrm{RO}}$ per bending angle is $0.216(=2700 / 12500)$. To put these values in some context, Fisher (2003) estimated the DFS of 40 AMSU-A radiances from 5 profiles within a $2^{\circ} \times 2^{\circ}$ box as DFS ${ }_{\mathrm{AMSUA}}=2.6162$. In addition, the DFS of AIRS estimated from $60 J_{\mathrm{b}}$ values from 1 to 30 March 2004 is DFS $\mathrm{DIRS}=6970 \pm 140$, around $10 \%$ of the total.

The relatively large $\mathrm{DFS}_{\mathrm{RO}}$ value (given the number of observations) is consistent with the results presented in section 4(b) because it indicates GPSRO measurements are introducing information that is not provided by other measurements. This is clear graphically from the temperature analysis differences shown in Fig. 5. However, the large value is also a consequence of the GPSRO measurements providing information in the lower stratosphere, where the background errors are relatively large because there are fewer observations.

\section{Discussion AND CONCLUSIONS}

The results illustrate that CHAMP GPSRO measurements clearly provide highquality temperature information in the upper troposphere and lower stratosphere, improving the r.m.s. fits to radiosonde temperature measurements, particularly in the SH 
(Fig. 7). The assimilation experiments have been performed with an NWP system which is close to that used operationally at ECMWF, and they have run for 60 days, so the results are considered statistically robust. One of the major strengths of GPSRO measurements-distinguishing them from other satellite measurements-is that they should not require bias correction, and it must be emphasized that we have not performed any bias correction of the bending angles with impact heights greater than $5 \mathrm{~km}$ used in this study. Consequently, GPSRO appears to be particularly good at identifying and partially correcting model biases in the upper troposphere and lower stratosphere (e.g. Fig. 6), which otherwise are difficult to correct because other satellite observations tend to be bias corrected to the model. This suggests that assimilating GPSRO observations may help to separate model and observation biases and therefore indirectly assist in the bias correction of other satellite measurements. However, it must be acknowledged that bending angles with impact heights less than $5 \mathrm{~km}$ are currently blacklisted because they are known to be biased low (Rocken et al. 1997; Ao et al. 2003).

The difficulties associated with the $P_{\mathrm{S}}$ increments introduced by the GPSRO measurements are of interest to NWP centres planning to assimilate GRAS and COSMIC data. We view the current modification of the tangent-linear and adjoint routines (in order to remove the sensitivity of the geopotential height values to changes in the $P_{\mathrm{s}}$ ) as a way of conveniently circumventing the problem, rather than as a long-term solution. One area which will be revisited in connection with this is the observation-error covariance matrix, R. Although, as noted in section 3(b), the GPSRO component of the observation cost function is close to unity (suggesting the errors are reasonable), it would be interesting to investigate the effect of introducing vertical error correlations on the $P_{\mathrm{S}}$ increments. We will also consider latitudinally varying observation-error variances, given that the representation errors appear to vary latitudinally (Fig. 10).

We have implemented a 1D bending-angle operator, which uses NWP profile information, with a view to testing a 2D operator, which requires NWP information from a planar section, in the near future. The principle aim of future work will be to compare forecast impact experiments which use 1D and 2D operators in an attempt to clearly demonstrate the benefit of using a more sophisticated and computationally expensive approach. Since the 2D model is expected to be more accurate near the surface, as a result of using the NWP forecast of the horizontal gradients, it may mitigate some of the difficulties with the increased $500 \mathrm{Z}$ errors encountered in this study. However, this has yet to be demonstrated and it is important to recognize that there are a number of reasons why the implementation of a 2D operator may not produce particularly dramatic improvements. Fundamentally, the observed bending-angle values are derived assuming the impact parameter value, $a$, has the same value at the Low Earth Orbiter and GPS satellites; introducing a new observation operator-which hopefully has smaller forward model errors-does not alter this fact. This may account for recent results presented by Poli and Joiner (2004, their Fig. 4) who found relatively small reductions in the standard deviation of their $\mathrm{O}-\mathrm{B}$ bending-angle statistics, when moving from a $1 \mathrm{D}$ bending-angle operator to a $2 \mathrm{D}$ version. Nevertheless, it has been argued (e.g. Zou et al. 1999) that, provided the same assumptions are made in the forward model and the observation processing, the horizontal gradient errors will essentially cancel out, because the assimilation is based on the difference between the observed and simulated values. Strictly, this may be true if the errors are accurately reproduced in the forward model, but it relies on the NWP model having adequate resolution to represent the horizontal gradients and the model providing a good forecast of them. For example, the T170 model used by Zou et al. (2004) is simply not able to reproduce the horizontal variations in refractivity shown in Fig. 3c of Healy (2001), and therefore 
it is not possible to simulate the horizontal gradient errors that would occur in that atmosphere. Further, the incremental formulation of 4D-Var (Courtier et al. 1994) calculates the analysis increments on a grid which is coarser than the NWP forecastmodel grid because the forecast errors are balanced and smooth. This fact is reflected in the eigenspectra of the 4D-Var B matrix. If an NWP forecast does not initially provide the correct high-resolution horizontal gradient information at the GPSRO observation location, it would be a mistake to expect it to be introduced during the assimilation of the GPSRO measurements because of (i) the spatial filtering properties of the $\mathbf{B}$ matrix and (ii) the poor horizontal resolution of the measurement. On the other hand, the horizontal resolution of NWP models is increasing. For example, by the end of 2005 ECMWF will run the forecast model at T799 resolution $(\sim 25 \mathrm{~km})$, and the incremental 4D-Var system will provide analysis increments at T255 $(\sim 78 \mathrm{~km})$. Hence, the development and implementation of 2D GPSRO observation operators remains an area of interest.

In summary, in these experiments we have found that the surface pressure increments introduced by the GPSRO observations degrade the SH 500Z forecast scores when verified against both observations and analyses. Modifying the relevant tangentlinear and adjoint code to reduce the $P_{\mathrm{s}}$ increments largely corrects these problems, although we note that a small degradation of the SH $500 \mathrm{Z}$ is still evident and needs to be resolved. However, the results are extremely encouraging in the upper troposphere and lower stratosphere. The GPSRO observations reduce model temperature biases over Antarctica and generally improve the r.m.s. forecast fit to radiosonde temperatures between 300 and $50 \mathrm{hPa}$ in the SH. Overall, the results clearly illustrate that GPSRO measurements can introduce useful, new information into a state-of-the-art NWP system, which is already assimilating of order 2.7 million conventional and satellite observations. The fact that this has been achieved with a single instrument, CHAMP, is extremely encouraging and suggests that GRAS and COSMIC measurements may become an important component of the global observing network from 2006.

\section{ACKNOWLEDGEMENTS}

The authors thank Niels Bormann, Sami Saarinen, Lars Isaksen and Christian Marquardt for their help during this study. The authors also acknowledge GFZ-Potsdam and UCAR for providing the CHAMP data and the EUMETSAT GRAS-SAF for providing the 1D bending-angle observation operator code. The figures were improved by Rob Hine. Sean Healy is supported through the EUMETSAT/ECMWF Fellowship Programme.

Abramowitz, M. and Stegun, I. (Eds.)

Andersson, E. and Järvinen, H.

Anthes, R., Rocken, C. and Kou, Y.

Ao, C., Meehan, T., Hajj, G., Manucci, A. and Beyerle, G.

Bean, B. and Dutton, E.

Cardinali, C., Pezzulli, S. and Andersson, E.

Collard, A. and Healy, S.

\section{REFERENCES}

1964

1999

2000

2003

1968

2004

2003
Mathematical functions with formulas, graphs, and mathematical tables. Dover Publications, New York, USA

Variational quality control. Q. J. R. Meteorol. Soc., 125, 697-722

Applications of COSMIC to meteorology and climatology. Terr., Atmos. Ocean. Sci., 11, 115-156

Lower troposphere refractivity bias in GPS occultation retrievals. J. Geophys. Res., 108, doi: 10.1029/2002JD003216

Radio Meteorology. Dover Publications, New York, USA

'Influence matrix diagnostic of a data assimilation system'. Technical memorandum 450, ECMWF, Reading, UK

The combined impact of future space-based atmospheric sounding instruments on numerical weather prediction analysis fields: A simulation study. Q. J. R. Meteorol. Soc., 129, 2741-2760 
Courtier, P., Thépaut, J.-N. and Hollingsworth, A.

Eyre, J.

Fisher, M.

Healy, S.

Healy, S. and Eyre, J.

2000

Healy, S., Jupp, A. and

Marquardt, C.

Hocke, $\mathrm{K}$.

Järvinen, H. and Undén, P.

Jensen, A., Lohmann, M., Benzon, H.-H. and Nielsen, A.

Klinker, E., Rabier, F., Kelly, G. and Mahfouf, J.-J.

Kuo, Y.-H., Sokolovskiy, S.,

Anthes, R. and

Vandenberghe, F.

Kuo, Y.-H., Wee, T.-K., Sokolovskiy, S., Rocken, C., Schreiner, W., Hunt, D. and Anthes, R.

Kursinski, E., Hajj, G., Bertiger, W., 1996 Leroy, S., Meehan, T.,

Romans, L., Schofield, J.,

McCleese, D., Melbourne, W., Thornton, C., Yunck, T., Eyre, J. and Nagatani, R.

Kursinski, E., Hajj, G., Schofield, J., Linfield, R. and Hardy, K.

List, R. (Ed.)

Liu, H., Zou, X., Shao, H., Anthes, R., Chang, J., Tseng, J.-H. and Wang, B.

Loiselet, M., Stricker, N., Menard, Y. and Luntama, J.-P.

Marquardt, C., Healy, S., Luntama, J.-P. and McKernan, E.

McNally, A. P., Watts, P. D. Smith, J. A., Engelen, R., Kelly, G. A., Thépaut, J.-N. and Matricardi, M.

Melbourne, W., Davis, E., Duncan, C., Hajj, G. Hardy, K., Kursinski, E., Meehan, T. and Young, L.

2000
A strategy for operational implementation of 4D-Var, using an incremental approach. Q. J. R. Meteorol. Soc., 120, 13671388

'Assimilation of radio occultation measurements into a numerical weather prediction system'. Technical memorandum 199, ECMWF, Reading, UK

'Estimation of entropy reduction and degrees of freedom of signal for large variational analysis systems'. Technical memorandum 397, ECMWF, Reading, UK

Radio occultation bending angle and impact parameter errors caused by horizontal refractive index gradients in the troposphere: A simulation study. J. Geophys. Res., 106, 1187511889

Retrieving temperature, water vapor and surface pressure information from refractive-index profiles derived by radio occultation: A simulation study. Q. J. R. Meteorol. Soc., 126, 1661-1683

2005 Forecast impact experiment with GPS radio occultation measurements. Geophys. Res. Lett., 32, L03804, doi: 10.1029/2004GL020806

Inversion of GPS meteorology data. Ann. Geophys., 15, 443-450

'Observation screening and background quality control in the ECMWF 3D-Var data assimilation system'. Technical memorandum 236, ECMWF, Reading, UK

2003 Full Spectrum Inversion of radio occultation signals. Radio Sci., 38, 1040, doi: 10.1029/2002RS002763

2000 The ECMWF operational implementation of four dimensional variational assimilation. Part III: Experimental results and diagnostics with operational configuration. Q. J. R. Meteorol. Soc., 126, 1191-1218

Assimilation of GPS radio occultation data for numerical weather prediction. Terr., Atmos. Ocean. Sci., 11, 157-186

Inversion and error estimation of GPS radio occultation data. J. Meteorol. Soc. Japan, 82, 507-531

Initial results of radio occultation observations of earth's atmosphere using the Global Positioning System. Science, 271, 1107-1110

Observing earth's atmosphere with radio accultation measurements using the Global Positioning System. J. Geophys. Res., 102, 23429-23465

Smithsonian meteorological tables. Smithsonian Institution Press, Washington DC, USA

2001 Impact of 837 GPS/MET bending angle profiles on assimilation and forecasts for the period June 20-30, 1995. J. Geophys. Res., 106, 31771-31786

2000 'Metop's GPS-based atmospheric sounder'. Bulletin 102, ESA, Darmstadt, Germany

2005 'GRAS level 1b product validation with 1D-Var retrieval'. Programme Development Department, Technical memorandum 12, EUMETSAT, Darmstadt, Germany

2006 The assimilation of AIRS radiance data at ECMWF. Q. J.R. Meteorol. Soc., 132, in press

1994 'The application of spaceborne GPS to atmospheric limb sounding and global change monitoring'. Publication 94-18, Jet Propulsion Laboratory, Pasadena, Calif., USA 
Poli, P. and Joiner, J.

2003

2004

Poli, P., Joiner, J. and Kursinski, E.

Rabier, F., Järvinen, H., Klinker, E., 2000 Mahfouf, J.-J. and

Simmons, A.

Rocken, C., Anthes, R., Exner, M., Hunt, D., Sokolovsky, S.,

Ware, R., Gorbunov, M.,

Schreiner, W., Feng, D.,

Herman, B., Kuo, Y.-H. and Zou, X.

Rodgers, C. D.

Simmons, A. and Burridge, D.

Simmons, A. and Hollingsworth, A. 2002

Tsuda, T., Nishida, M., Rocken, C. 2000 and Ware, R.

Wickert, J., Reigber, C.,

Beyerle, G., König, R.,

Marquardt, C., Schmidt, T.,

Grunwaldt, L., Galas, R.,

Meehan, T., Melbourne, W. and Hocke, $\mathrm{K}$.

Zou, X., Vandenberghe, F., Wang, B., Gorbunov, M., Kuo, Y.-H., Sokolovsky, S., Chang, J., Sela, J. and Anthes, R.

Zou, X., Liu, H., Anthes, R., Shao, H., Chang, J. and Zhu, Y.-J.

1999
'Assimilation experiments of one-dimensional variational analyses with GPS/MET refractivity'. Pp. 515-520 in First CHAMP mission results for gravity, magnetic and atmospheric studies. (Eds.) C. Reigber, H. Luhr and P. Schwintzer

Effects of horizontal gradients on GPS radio occultation observation operators. I: Ray tracing. Q. J. R. Meteorol. Soc., 130, 2787-2805

1D-Var analysis of temperature and humidity using GPS radio occultation refractivity data. J. Geophys. Res., 107, 4448, doi: 10.1029/2001JD000935

The ECMWF operational implementation of four dimensional variational assimilation. I: Experimental results with simplified physics. Q. J. R. Meteorol. Soc., 126, 1143-1170

Analysis and validation of GPS/MET data in the neutral atmosphere. J. Geophys. Res., 102, 29849-29866

Inverse methods for atmospheric sounding: Theory and practice. World Scientific Publishing, Singapore

1981 An energy and angular momentum conserving vertical finite difference scheme and hybrid coordinate. Mon. Weather Rev., 109, 758-766

Some aspects of the improvement in skill of numerical weather prediction. Q. J. R. Meteorol. Soc., 128, 647-677

A global morphology of gravity wave activity in the stratosphere revealed by the GPS occultation data (GPS/MET). J. Geophys. Res., 105, 7257-7273

2001 Atmosphere sounding by GPS radio occultation: First results from CHAMP. Geophys. Res. Lett., 28, 3263-3266

A ray-tracing operator and its adjoint for the use of GPS/MET refraction angle measurements. J. Geophys. Res., 104, 22301-22318

Impact of CHAMP radio occultation observations on global analyses and forecasts in the absence of AMSU radiance data. J. Meteorol. Soc. Japan, 82, 533-549 